\title{
Internationalisation of patents by Public Research Organisations from a historical and an economic perspective*
}

\author{
Ana Romero-de-Pablos ${ }^{*}$ and Joaquín M. Azagra-Caro ${ }^{* *}$ \\ *anaromero@ifs.csic.es \\ Department of Science, Technology and Society, Institute of Philosophy (CSIC), Albasanz 26-28, 28037 Madrid \\ (Spain) \\ **joaquin-maria.azagra-caro@ec.europa.eu \\ INGENIO (CSIC-UPV) and IPTS (European Commission - Joint Research Centre), Edificio Expo, Inca \\ Garcilaso s/n, E-41092 Sevilla (Spain)
}

\begin{abstract}
Within the field of the organisation of science, concerns about how academics generate patents tend to focus on a single set of either national or international patents. The main aim of this research is to study both national and international patenting in order to understand their differences. We have approached this issue from both a historical and an economic perspective, using data from the Spanish National Research Council (CSIC), the largest PRO in Spain. Three periods can be distinguished in the CSIC's history, according to the political context, namely the dictatorship (1939-1975), the transition to democracy (1976-1986) and democracy (1987-to date). The prevailing legal and institutional framework has marked the way in which patenting by CSIC has evolved in each of these periods. The current situation is one in which there is strong internationalisation of patenting activity, and in this most-recent period we explore trends in some of the economic influences on patenting activity. We conclude that the political and normative context may shape the culture of international patenting at PROs like the CSIC and that increasing technological cooperation has supported this internationalisation. However, very often foreign partners are included in the application in order to extend protection abroad for commercial reasons, so their number may not be a good indicator of inventive activity.
\end{abstract}

\section{Keywords}

Academic patents, internationalisation, PROs

\section{Introduction}

University patents have become an important object of analysis because they reflect changes in knowledge production and diffusion; they are an indicator of research results that may be taken into account in the evaluation of merits and a potential instrument for technology transfer. Studies carried out to date have tended to apply a single disciplinary perspective, e.g. historical (Mowery and Sampat, 2001; Metlay, 2006), economic (Feller, 1990; Pavitt, 1998), or scientometric, etc.

Elsewhere we have shown that similar debates should be extended to the other main knowledge producer in the public R\&D system, namely Public Research Organisations (PROs), and that a multidisciplinary approach allows for a richer interpretation of the results (Azagra and Romero, 2006). In this paper we apply this philosophy to the study of a question that is little examined in the literature: what are the factors leading academic institutions to patent abroad? While most studies focus their attention on just one set of patents, one of the authors has shown that differences among sets of patents matter in the analysis of how they are generated, e.g. national vs. international patents, since they may lead to normative conclusions (Azagra, Yegros and Archontakis, 2006).

Our object of study will be the Spanish Council for Scientific Research (CSIC), the largest PRO in Spain according to its historical trajectory, its resources, its wide regional implantation and its

\footnotetext{
* This work was supported by CSIC's Science, Technology and Innovation (CTI) Network. The research was mostly performed when Joaquín M. Azagra-Caro worked at INGENIO, but since the $1^{\text {st }}$ of December 2006, he has been working at the JRC IPTS. The views expressed in this article are the authors' and do not necessarily reflect those of the European Commission. Neither the European Commission nor any person acting on behalf of the Commission is responsible for the use that might be made of the following information.
} 
multidisciplinarity across research units. It is also very active in patenting, currently accounting for more than 10 percent of Spanish patent applications.

\section{Patent internationalisation processes}

Sovereign states legislate on intellectual property rights. Inventors can apply for a patent through their respective national patent offices. Most developed countries now allow universities to apply for patents and license them.

The traditional way to protect knowledge abroad is to apply for a patent in the foreign country concerned, which requires a separate administrative procedure in each country. To simplify this process, some countries have signed international treaties allowing applications for patents in their territory to be made through a common procedure. Citizens of the participating countries can designate in which of these countries they want protection, including their own.

A country's decision to promote internationalisation by means of a treaty is a specific regulatory change which deserves attention. The aim is not to increase the number of patents per se but to facilitate patenting abroad. However, this option may make patenting more attractive to applicants, thus increasing the number of patents overall.

Most European countries participate in two main pacts of this kind. The first is the Patent Cooperation Treaty (PCT) (Washington, 1970), which gave rise to the so-called PCT patent. The second is the European Patent Agreement (EPA) (Munich, 1973), which gave rise to the so-called European Patent ${ }^{1}$. Applications are made through the International Office of the World Industrial Property Organisation and the European Patent Office (EPO), respectively, but national patent offices may also start the procedure. ${ }^{2}$ However, we should point out that, unlike the EPA, the PCT system does not directly lead to the granting or refusal of a patent. Rather it provides a uniform procedure for processing and handling applications.

\section{From dictatorship to democracy in Spain: milestones in the history of internationalisation of the CSIC}

The CSIC was created after the civil war in 1939. The new leaders felt that the best way to control and organise research activity was to group or divide it into boards. The history of the Board of Technical Research (Patronato Juan de la Cierva, hereafter PJC) and therefore the work carried out at its offices cannot be studied separately from the situation in which Spain found itself, not only after the civil war but also after the Second World War. Spain's difficult international position, in addition to the regime's political need not to acknowledge anything prior to 1936, turned this external and internal isolation into a liability that took a long time to eradicate. In the post-war situation, the individual interests of companies had to give way to national interest, and this shaped the structure of the CSIC as the overall aim was to make it the basis of the mobilisation of science to serve the major national concerns.

1977 was a year of change for the CSIC: a new internal structure was put into place which included the first democratic mechanisms. 1986, which was a watershed in Spanish science policy, is the last of the outstanding historical milestones for this article. This was the year in which the Act to Promote and Generally Coordinate Scientific and Technical Research, the so-called "Science Act" (Act 13/1986, Official State Bulletin of 18th April 1986), was passed. Although this Act must also be viewed in the context of Spain's joining the European Economic Community, we should not forget that it was the result of the growing awareness of the importance of scientific research for Spain. The new organisational design and control mechanisms created by the Act were intended to be more effective, so as to be capable both of managing new funding and handling the creation of initiatives such as the National Plan for Scientific Research and Technological Development in 1988. However,

\footnotetext{
${ }^{1}$ This should not be confused with the existing project of enabling a single patent for all members of the European Union.

${ }^{2}$ There is a procedure for PCT extensions to designate Europe for protection, that is to say, all the countries that signed the EPA. It makes it unnecessary to designate each one separately and reduces bureaucracy, since the EPO handles the application instead of several national offices. This procedure, called PCT-European route, is equivalent to applying for a patent through the European route if no further countries outside the EPA are designated.
} 
the Act also sought to provide a response to the new situations brought about by the arrival of democracy.

The engagement in the process of internationalisation of patents also received strong regulatory support during this period. In July 1986, although it did not become effective until October 1987, Spain joined the EPA. Another important factor to bear in mind is Spain's joining the PCT, which came into force in November 1989. The PCT system normally used by the CSIC to place its patents on the international market has advantages, as it facilitates the application procedure at an international level.

\section{Data and methods}

\section{The historical approach}

The patent data used in this article come from various sources. For the case of patents applied for during the period when the CSIC was organised into Boards (1939-1975), the historical database of the Spanish Patents and Trademarks Office (OEPM) was used. Here we could only find patents applied for by the PJC, despite our exhaustive search for patents applied for by all the Boards. We subsequently completed and compared the database with data from the PJC Annual Reports.

The data used for the period 1975 to 2005 were those kept by the CSIC's Technology Transfer Office (TTO) together with a database generated using information published in the CSIC's Annual Reports, which allowed us to associate CSIC patents with specific research units and, through these, to ascribe them to specific scientific areas and regions.

The first patents registered by the OEPM from the PJC were in 1949, the year when the analysis therefore starts. Chronologically, three periods have been established. These respond to the historical and legislative changes already mentioned. The first period runs from 1949 to 1975, the year when structural changes in the CSIC brought about the disappearance of the boards. The second, shorter, period extends from 1976 to 1986, the year when Spain joined the EEC and two Acts were passed which were decisive for patents in Spain: the Patent Act and the Science Act. The third period started in 1987 and lasted until 2005. Within this time framework, we have analysed the variations in patent applications, the scientific areas concerned, the spatial distribution, collaboration with other groups or research units and the connections between Spanish scientists and the outside world.

The economic approach ${ }^{3}$

The more recent data is more detailed, so the question is how to choose the appropriate cut-off point. The historical approach justifies defining the late period, 1987-2005, for the economic analysis, given the more uniform legal and institutional framework. This is an example of cross-fertilisation between the two approaches.

The historical approach employs data from the CSIC's TTO in the late period that we also use here. It consists of a set of 2,793 patents applied for by the CSIC. We classified them by an average of 95 CSIC research units per year and 19 years (1987-2005), so we built a 1,812-observation panel. As far as we are aware, this is one of the largest databases in Europe for the study of public patents at the institutional level.

We applied count data econometric models in order to estimate the determinants of CSIC patents. The independent variables include those on collaboration patterns from the same TTO database: logarithm of number of co-applicants, by type (other CSIC research units, other PROs, universities ${ }^{4}$, businesses and other institutions) and nationality (Spanish and foreign).

A second database from the CSIC's annual reports allows us to include other independent variables on the research units' characteristics. These are total staff (in logs) and their composition (proportion of

\footnotetext{
${ }^{3}$ Strictly speaking, this is a microeconomic approach. A macroeconomic approach to analysing whether patent internationalisation by PROs has any impact on the overall economy is beyond of the scope of this paper and could be a subject for further research.

${ }^{4}$ According to Spanish law, patents applied for by joint centres have both the CSIC and the relevant universities as the assignees. We consider that technological cooperation has taken place only when CSIC research units apply for a patent with a university of which they do not form part. Therefore, we checked cases of joint applications by the CSIC and a university individually and counted only those in the situation described.
} 
CSIC civil servants, CSIC working staff, university personnel and other personnel -mainly temporary), amount of financial activities per capita (national projects, other projects, contracts, in $\operatorname{logs}$ ), scientific area, region ${ }^{5}$ and being part of a service centre -an institution for the joint management of research units.

We are looking at research units, and some of them may behave like outliers that we have to detect. Actually, there is one in the sample, the Institute of Chemistry (ITQ) ${ }^{6}$, so we created a dummy variable to allow it to have a separate intercept.

Finally, we controlled for time differences over the length of each CSIC presidency under each political party in the government. There were eight CSIC presidents and three political parties in Spain during the period of observation.

\section{The growth of international patenting by the CSIC, 1949-2005}

\section{9-1975: limited internationalisation}

Although only sixteen PJC applications were registered outside Spain in this first period, it is worth devoting them some attention. 1971 was the first year when Spanish patents were registered abroad. Places in Europe such as France, Belgium, Great Britain, Germany, Italy, Holland, Poland, Norway, Yugoslavia, Russia and Turkey were chosen. Nevertheless, Spanish interest did not focus solely on Europe; the data indicate that patents were also registered outside the continent: the other countries reached by PJC patents being the United States, Canada, Mexico, Brazil, Argentina, Peru, Morocco, Algeria, Japan and Australia. Spain's position after the Second World War, in particular the regime's policy of autarky, and the subsequent agreements with the United States, all undoubtedly affected the country's scientific life. Nevertheless, this is perhaps an appropriate point at which to mention the Cultural Relations Board, an organisation dependent on the Ministry of Foreign Affairs, as it allows us to tackle an important point when analysing the use abroad of knowledge generated by the CSIC, namely the training of Spanish scientists in foreign research centres. This was one of the underlying principles of the JAE, the CSIC's precursor, and forms part of the legacy that José Maria Albareda, general secretary/junior minister of the CSIC, took on and tried to strengthen (Delgado and Elizalde, 2005). This situation is explained by the relations established by the scientists themselves.

\section{6-1986: incipient internationalisation}

In this period, between 1976 and 1986, some degree of internationalisation also took place. There were sixteen patent applications for protection outside Spain. In Europe, the countries where patents were applied for were Germany, Belgium, France, Holland, Italy and Yugoslavia. This period was also marked by an outstanding lack of presence of Spanish research abroad. In this period the focus was on the internal organisation of the body, starting up new policies and implementing new regulations whose results would be felt in later years.

\section{7-2005: strong internationalisation}

This period saw an increase in patent applications, starting in the 80 's and continuing into the mid-90 when there was another significant jump. Table 1 allows us to evaluate more precisely what this growth really meant. First are the total patent applications by the CSIC throughout this period. In the next three columns, there is a breakdown of this total. The second column includes each year's applications in Spain. The third column shows foreign applications directly applied for abroad through national procedures. The final column contains data on international extensions, i.e. families of the two former sets, generated following patent applications through an international procedure.

The data for total applications in this period show growth at the end of the 80 's which, over the years, not only consolidates but even almost triples during the following years. This growth not only justifies the necessary legislation on patents but is also a reflection of the different regulations initiated during the last few years of the 70 's and principally the 80 's. This is the time when, within the Ministry of

\footnotetext{
${ }^{5}$ We refer to 10 Spanish NUTS-2 regions plus Rome. We take Castile-Leon and Balearic Islands as a benchmark.

${ }^{6}$ ITQ holds $20 \%$ of all patent applications. The next research unit just holds $8 \%$.
} 
Education and Science, the Secretary of State for Universities and Research and the General Directorate of Scientific Policy were created.

During the late 80's, the number of CSIC Spanish applications almost coincided with the number of CSIC total applications. Up until 1995 they accounted for more than 50 percent. From 1995 onwards, there was a reversal and international patents (the sum of foreign applications plus international extensions) came to account for more than half of the total. As already mentioned, a change took place after Spain joined the European Community, with all this entailed. Of course, after the EPA and the PCT came into force direct foreign applications are rare as compared with international extensions.

Table 1. CSIC patent applications (1987-2005)

\begin{tabular}{lllll}
\hline Years & Total & $\begin{array}{l}\text { Spanish } \\
\text { applications }\end{array}$ & Foreign applications & $\begin{array}{l}\text { International } \\
\text { extensions }\end{array}$ \\
\hline 1987 & 9 & 9 & 0 & 0 \\
\hline 1988 & 19 & 19 & 0 & 0 \\
\hline 1989 & 45 & 43 & 0 & 2 \\
\hline 1990 & 62 & 42 & 0 & 20 \\
\hline 1991 & 54 & 25 & 1 & 28 \\
\hline 1992 & 44 & 27 & 0 & 17 \\
\hline 1993 & 68 & 31 & 0 & 37 \\
\hline 1994 & 65 & 37 & 0 & 28 \\
\hline 1995 & 57 & 37 & 0 & 20 \\
\hline 1996 & 102 & 51 & 0 & 51 \\
\hline 1997 & 142 & 63 & 1 & 78 \\
\hline 1998 & 190 & 63 & 3 & 124 \\
\hline 1999 & 243 & 94 & 4 & 145 \\
\hline 2000 & 238 & 101 & 4 & 133 \\
\hline 2001 & 250 & 98 & 1 & 151 \\
\hline 2002 & 342 & 123 & 2 & 217 \\
\hline 2003 & 316 & 94 & 3 & 219 \\
\hline 2004 & 251 & 102 & 4 & 145 \\
\hline 2005 & 296 & 111 & 8 & 177 \\
\hline Total & 2793 & 1170 & 31 & 1592 \\
\hline & & & & \\
\hline
\end{tabular}

A variety of information is available making it possible to analyse these data in more detail. The countries that received the greatest number of Spanish patent applications between 1987 and 2005 were the United States (154), Japan (69), Canada (65), the United Kingdom (54) and France (50). Other interesting facts are that, during this period, 487 applications were processed in the international market via the PCT treaty and 168 applications were processed via the EPA. These data suggest institutional strategies but at the same time, and related to the previous point, they also lead us to think some scientific areas are more highly internationalised than others.

An analysis of patent families according by scientific area offers an answer to the question as to whether there are areas which are more accustomed to applying for patents abroad or traditionally have a stronger propensity to do so. Because the areas of Chemistry and Biology \& Biomedicine are those applying for most patents, both nationally and internationally, a difference can be seen in the countries designated to obtain protection. In the Chemistry area, it is of interest to protect knowledge most in the United States, then in Japan, Canada, the United Kingdom and France. On the other hand, in the area of Biology \& Biomedicine, patents were applied for in countries such as the United States, Canada and Japan and, unlike the previous case, Australia. 
Table 2. Determinants of the number of CSIC patents by research unit and year

\begin{tabular}{|c|c|c|}
\hline & Number of CSIC Spanish applications & Number of CSIC international extensions \\
\hline Best-fit model & Zero Altered Neg. Binomial Regression & Negative Binomial Regression \\
\hline Number of observations & 1,812 & 1,812 \\
\hline Poisson-associated $\mathrm{R}^{2}$ & 0.55 & 0.76 \\
\hline Log likelihood function & $-1,363.13$ & $-1,098.77$ \\
\hline \multirow[t]{2}{*}{$\operatorname{Prob}\left[\chi^{2}>\right.$ value $]=$} & 0.00 & 0.00 \\
\hline & Coeff. (t-ratio) & Coeff. (t-ratio) \\
\hline Constant & $-1.51(-5.6) * *$ & $-10.03(-11.47) * *$ \\
\hline \multicolumn{3}{|l|}{ Technological cooperation with } \\
\hline Other CSIC research units & $0.74(5.39) * *$ & $0.42(2.19) *$ \\
\hline Other national PROs & $1.16(1.96) *$ & $1.79(2.66) * *$ \\
\hline Foreign PROs & $1.56(0.33)$ & $1.02(3.58) * *$ \\
\hline National universities & $0.78(6) * *$ & $0.51(2.88) * *$ \\
\hline Foreign universities & $0.7(1.6)$ & $0.66(2.06) *$ \\
\hline National business firms & $1(4.21) * *$ & $1.29(8.29) * *$ \\
\hline Foreign business firms & $0.13(0.09)$ & $1.18(4.73) * *$ \\
\hline Other institutions & $-0.25(-0.38)$ & $1.3(1.49)$ \\
\hline \multicolumn{3}{|l|}{ Human capital } \\
\hline Total staff & $0.33(6.54) * *$ & $1.49(10.86) * *$ \\
\hline Proportion of CSIC civil servants & $-0.04(-0.28)$ & $1.79(3.52) * *$ \\
\hline Proportion of CSIC working staff & $-0.67(-2.78) * *$ & $-3.25(-3.02) * *$ \\
\hline Proportion of university personnel & $-0.55(-3.21) * *$ & $-0.72(-1.02)$ \\
\hline \multicolumn{3}{|l|}{ Financial capital } \\
\hline National projects & $0.06(2.03) *$ & $-0.09(-0.79)$ \\
\hline Other projects & $0.03(1.46)$ & $0.14(1.58)$ \\
\hline Contracts & $0(0.09)$ & $0.03(0.55)$ \\
\hline \multicolumn{3}{|l|}{ Scientific area } \\
\hline Chemistry & $0.41(5.95) * *$ & $0.91(4.77) * *$ \\
\hline Food & $0.4(4.95) * *$ & $0.63(2.62) * *$ \\
\hline Materials & $0.35(4.98) * *$ & $-0.09(-0.45)$ \\
\hline Agriculture & $0.11(1.71)$ & $-0.4(-1.37)$ \\
\hline Natural resources & $-0.15(-2.47) * *$ & $-1.38(-3.94) * *$ \\
\hline \multicolumn{3}{|l|}{ Region } \\
\hline Andalusia & $0.16(1.87)$ & $0.94(1.82)$ \\
\hline Valencian Community & $0.13(1.27)$ & $0.78(1.42)$ \\
\hline Madrid & $0.08(0.98)$ & $0.76(1.46)$ \\
\hline Asturias & $0.19(0.99)$ & $-28.89(-0.32)$ \\
\hline Catalonia & $-0.01(-0.15)$ & $0.15(0.27)$ \\
\hline Galicia & $0.04(0.39)$ & $-1.22(-1.45)$ \\
\hline Aragon & $-0.06(-0.6)$ & $0.61(1.04)$ \\
\hline Murcia & $-0.14(-0.87)$ & $0.65(0.91)$ \\
\hline Canary Islands & $-0.23(-1.51)$ & $0.7(0.99)$ \\
\hline Service centre & $0.22(4) * *$ & $0.92(5.56) * *$ \\
\hline ITQ & $1.82(12.39) * *$ & $3.74(8.16) * *$ \\
\hline \multicolumn{3}{|l|}{ CSIC president_Party in the government } \\
\hline Pres1_Party1 & $-0.08(-1.2)$ & $-3.46(-3.8) * *$ \\
\hline Pres2 Party1 & $0.08(1.23)$ & $-0.29(-1.01)$ \\
\hline Pres3_Party1 & $-0.13(-1.08)$ & $0.15(0.29)$ \\
\hline Pres4_Party2 & $0.09(0.44)$ & $0.06(0.08)$ \\
\hline Pres5_Party2 & $0.13(2.34) * *$ & $0.86(4.03) * *$ \\
\hline Pres6_Party2 & $0.22(3.35) * *$ & $1.41(6.12) * *$ \\
\hline Pres7_Party2 & $0.14(1.71)$ & $1.04(3.37) * *$ \\
\hline Pres8_Party1 & $0.17(1.49)$ & $1.86(5.07) * *$ \\
\hline$\alpha$ & $0.13(2.14) *$ & $1.33(8.68) * *$ \\
\hline$\tau$ & $-5.24(-5.37) * *$ & \\
\hline
\end{tabular}

Determinants of CSIC international patents by research unit in the late period, 1987-2005

In Table 2 we show our favourite specifications according to the tests conducted: a zero inflated negative binomial model for Spanish national patents and a standard negative binomial regression for 
international extensions. We did not try to fit a model for direct international patents since their number was so small.

According to the estimates, cooperation with other national PROs and national businesses has the largest positive effect on patent production ${ }^{7}$. Having other CSIC research units and Spanish universities as co-applicants also enhances national patent production, but to a lesser extent. Cooperation with other institutions does not have a significant effect on the production of CSIC patents. Until now, this has been valid for both national and international patents. When it comes to foreign partners, some differences arise. While cooperation with foreign PROs, foreign universities and foreign firms is not significant in terms of increasing national patents, it is positively significant for increasing international patents.

Regarding human capital, the higher the number of total staff, the more likely it is that CSIC research units will generate national and international patents.

Research units with a higher proportion of CSIC civil servants ( $42 \%$ on average) patent through the national route as much as those with a higher proportion of other personnel -the benchmark $(38 \%$ on average). Research units with a higher proportion of CSIC working staff (10\% on average) and university personnel (10\% on average) patent significantly less than the former through the national route. ${ }^{8}$ Having a higher proportion of CSIC civil servants also boosts the number of applications for international patent extensions, whereas a higher proportion of CSIC working staff also diminishes it. Regarding financial capital, the per capita number of national projects leads to a higher number of national patents but not to more extensions. No other funding actions are conducive to more patents.

It is important to control for differences between scientific areas, since some of them have a higher propensity to patent. The ranking is as follows: Chemistry and Food areas patent more than the average; Materials has also more national patents but not more international patents than the average; Physics, Biology \& Biomedicine and Agriculture represent the average; Natural Resources patent less than average.

We have also controlled for regional variation, which does not seem to affect patenting. On the other hand, being part of a service centre is highly positive for patenting.

The ITQ is actually an outlier. Its propensity to apply for patents needs to be controlled for in order to moderate the impact of other effects. The significant positive sign indicates that it stands out from other research units in terms of both national and international patents.

The effect of successive CSIC presidencies allows us to distinguish between two sub-periods during the period of observation. The propensity of CSIC research units to apply for international patent protection significantly increased from the fifth president onwards. This corresponds to the shift attributed to internationalisation by the historical approach. The impact is not so clear-cut in the case of national patents, however. Although there was an increase under presidents 5 and 6 , this was not subsequently sustained.

By contrast, it is worth noting that under president 4 patenting activity was the same regardless of whether party 1 or 2 was in government ${ }^{9}$. Moreover, the rise of patents continued at the end of the period regardless of which party was in power. This suggests that changes of government have not been influential.

\footnotetext{
${ }^{7}$ Due to the limited extension of the paper, here we focus the interpretation of the models in the distinction between national patents and international extension. For more discussion on the implications of the models, see Azagra and Romero (2006).

${ }^{8}$ Carayol and Matt (2004) find that the combination of permanent and temporary researchers enhances patenting as does the combination of full time researchers and university professors -at least in their Class 4 labs. Our results lead agree with the former but not with the latter finding. More evidence on the negative trade-off between teaching and research can be found in Azagra, Yegros and Archontakis (2006), where one of the present authors found that the existence of joint research centres was not sufficient for increased patenting by universities. It looks as though mixing research with teaching has advantages and costs and the outcome depends on the context (Martin, 2003).

${ }^{9}$ Pres4 Party1 is the benchmark.
} 


\section{Conclusions}

From the historical point of view, the eventual configuration of a clearer institutional and legal framework has bolstered the CSIC's international patenting. In 1986, the so-called Science Act came into force, in conjunction with Spain's joining the European Union and the enactment of the Spanish Constitution and the country's territorial and administrative reorganisation.

The late eighties were also crucial because numerous other legislative changes took place. Until 1986, patent law in Spain had not been reformed since 1929. Spain's joining the European Union forced it to adapt to European legislation. The 1986 Patent Act made it possible for Spain to patent chemical, pharmaceutical and food technologies for the first time. Moreover, in July 1986 Spain joined the EPA, which allowed patent applications to be made through a centralised system. Soon afterwards, Spain joined the PCT, the system most extensively used by the CSIC to internationalise its patents.

Once this general framework was in place, the economic approach shows that the effect on the rise in international extensions by the CSIC became significant after a lag of a few years, when the presidential style of the CSIC assumed these cultural changes. Moreover, the changes were solid enough as to be independent of later changes of the political party in government. One could speculate as to whether the absence of any influence by more recent governments is due to parties on both left and right no longer espousing different approaches to PRO patents.

The historical approach finds that technological cooperation has tended to stimulate the CSIC to make patent applications. There is a parallelism between the increase in the number of patents and the increase in the number of participants in their production. Moreover, this process runs in parallel with the trend towards the internationalisation of patents, which it is not merely a coincidence.

The economic approach quantifies the impact of technological cooperation in the later period and finds a significant relationship with patenting at the CSIC. While domestic partners are more conducive to patent production in general, foreign partners are also advantageous for international extensions. A second reading is that once the CSIC has applied for Spanish patents, it searches for foreign partners to help it extend protection abroad ${ }^{10}$. Hence, foreign institutions, especially foreign firms, are expected to provide commercial expertise rather than inventive knowledge. Studies on a single set of patents which predict that a higher number of foreign applicants will increase the number of patents should be cautious about the interpretation of the reasons why it may occur.

\section{References}

Azagra-Caro, J. M. \& Romero-de-Pablos, A. (2006). Patenting at public research organisations: a historicaleconomic approach, DIME-Universities Working Paper Series, http://uil.dime-eu.org/views/uil_publications.

Azagra-Caro, J. M., Yegros-Yegros, A. \& Archontakis, F. (2006). What do university patent routes indicate at regional level? Scientometrics 66 (1): 219-230.

Carayol, N. \& Matt, M. (2004). Does research organization influence academic production? Laboratory evidence from a large European university. Research Policy, 33, 1081-1102.

Delgado, L. \& Elizalde, M. D. (Eds.). (2005). España y Estados Unidos en el siglo XX. Madrid: Consejo Superior de Investigaciones Científicas.

Feller, I. (1990). Universities as engines of R\&D-based economic growth: They think they can. Research Policy, $19,335-348$.

Martin, B. (2003). The changing social contract for science and the evolution of the university. In A. Geuna, A. J. Salter \& W. E. Steinmueller (Eds.), Science and Innovation. Cheltenham: Edward Elgar.

Metlay, G. (2006). Reconsidering Renormalization: Stability and Change in 20th-Century Views on University Patents. Social Studies of Science, 36 (4), 565-597.

Mowery, D. C. \& Sampat, B. N. (2001). University Patents and Patent Policy Debates in the USA (1925-1980). Industrial and Corporate Change, 10 (3), 781-814.

Pavitt, K. (1998). Do patents reflect the useful research output of universities? Research Evaluation, 7, 2, 10511.

\footnotetext{
${ }^{10}$ We tried to verify this statement by taking a closer look at patent families and found that it is not rare for extensions to have more applicants than the original patent. A manager at the CSIC's TTO conformed verbally that this makes sense since it is part of CSIC's strategy.
} 